\title{
Cosmetic Serum Containing Grape (Vitis vinifera L.) Seed Extract Phytosome: Formulation and in vitro Penetration Study
}

\author{
Silvia Surini*, Helmy Mubarak, Delly Ramadon \\ Laboratory of Pharmaceutics and Pharmaceutical Technology Development, Faculty of Pharmacy, Universitas Indonesia, Depok 16424, INDONESIA.
}

\begin{abstract}
Objective: Grape seed extract (GSE) contains abundant phenolic compounds with high antioxidant activity. Phenolic compounds in GSE have an inadequate penetration due to its hydrophilicity. The objective of this research was to formulate GSE phytosome serum to overcome its penetration problem. Methods: Phytosomes were prepared in three formulas based on the mass ratio between the extract and the phosphatidylcholine, 1:0.5, $1: 1$, and $1: 2$, using the thin layer hydration method. Phytosomes were then characterized their morphology, particle size distribution, zeta potential and their entrapment efficiency. The selected phytosome was formulated into a gel-based serum. Then, physicochemical evaluations of the serum, including organoleptic test (color, odor, and syneresis), homogeneity, $\mathrm{pH}$, viscosity and rheology properties, were conducted. An in vitro penetration study using the Franz diffusion cells was performed on phytosome and nonphytosome serum (as a control). Results: The results showed that F2 was the optimal phytosome among other formula with a spherical shape, $D_{\text {me }}$ volume was $398.23 \mathrm{~nm}$, zeta potential at $-25.2 \mathrm{mV}$ and entrapment efficiency of $75.01 \pm 0.25 \%$. The cumulative amount of total phenolic
\end{abstract}

penetrated from the phytosome serum and control were $27.25 \pm 0.67 \%$ and $11.97 \pm 0.49 \%$, respectively. The phytosome serum had a flux value of $243.11 \pm 7.94 \mu \mathrm{g} / \mathrm{cm}^{2}$.hour, while the control serum was $68.56 \pm 5.54 \mu \mathrm{g} / \mathrm{cm}^{2}$. hour. Conclusion: This research demonstrated that phytosome could increase the penetration of the drug in serum dosage form.

Key words: Franz diffusion Cell, Grape seed extract, Penetration, Phytosome, Serum, Total phenolic.

\section{Correspondence}

Silvia Surini, Laboratory of Pharmaceutics and Pharmaceutical Technology Development, Faculty of Pharmacy, Universitas Indonesia, Depok 16424 INDONESIA.

Phone: $+62-21-7270031$

Email: silvia@farmasi.ui.ac.id

DOI: 10.5530/jyp.2018.2s.10

\section{INTRODUCTION}

Grapes (Vitis vinifera L.) and its seeds contain many important compounds. They are vitamins, minerals, lipids, proteins, carbohydrates, and complex of polyphenol compounds, especially catechin monomers, or dimers, trimers, and oligomers commonly known as proanthocyanidins. ${ }^{1-3}$ Researcher reported that grape seed extract significantly suppressed the formation of melanin pigment, as the result shown in UV-induced hyperpigmentation guinea pig. ${ }^{4}$ The pigmentation process of the skin occurs in the basal layer of the epidermis containing melanocyte cells, the cells that play a role in the formation of melanin pigment. Melanin is formed by oxidation process and enzymatically catalyzed by the tyrosinase enzyme. ${ }^{5}$ Polyphenolic compounds in grape seed extract (GSE) should penetrate into the basal layer of the epidermis to prevent the oxidation process of tyrosine to dopaquinone, thereby it has ability to reduce the risk of hyperpigmentation. ${ }^{6}$

Utilization of GSE as an active ingredient in topical dosage form has limitations regarding penetration, due to its hydrophilic nature. For example, proantocyanidin as the main compound of GSE has a log $\mathrm{P}$ value of $-0.31 \pm 0.02$ indicating its hydrophilic properties. While semipermeable cell membranes on the skin have a $\log \mathrm{P}$ value of about 2 to 3 . This condition leads to the need of structural modification to increase lipophilicity. ${ }^{7}$ One of strategies to enhance drug absorption and penetration of active ingredients from plant extracts is using the phytosome system. The application of phytosome technology to topical dosage form has proven to be effective for herbal medicine delivery into the skin. ${ }^{8}$

Phytosome enhance the penetration profile of active ingredient by converting hydrophilic environment conditions into lipophilic conditions according to the cell membrane environment. Component that is able to change the nature of flavonoids to lipophilic is phospholipid. Phospholipids are molecules of cell membranes that are soluble in water and fat. ${ }^{9}$ The phytosome formulations are not identical to oral dosage forms but may also be applied to semisolid dosage forms. An appropriate carrier system selection in topical preparations will give a great influence in drug absorption and have a beneficial effect for its delivery. ${ }^{10}$

In this study, a serum was selected as a formulated dosage form because of its rapid growth in the cosmetic industry, particularly in face lightening product. Serum begins to develop for several reasons, such as changes in consumer's lifestyle who want to simplify the use of cosmetics for time saving so that the selected form of concentrate is considered to have a better effect and the use of moisturizing technology based on skin physiology. Gel-based dosage forms are considered quite convenient to be used because it has a high content of water that can hydrate the skin and easily spread when applied. ${ }^{11-12}$

In this study, phytosomes were prepared containing GSE extract in various formulations. The formed phytosomes were characterized in terms of their morphology and shape, particle size distribution, zeta potential, and entrapment efciency to determine optimal formulation. The selected formulation was further produced to liquid gel based serum. Following the production, semi-solid evaluation of the serum and in vitro penetration study using Franz diffusion cells were performed to the phytosome serum. The control serum formulation of GSE was made as a comparison and the total phenolic content analysis was performed by using Folin Ciocalteu method. 


\section{MATERIALS AND METHODS}

\section{Materials}

Grape seed extract (Vitis vinifera $\mathrm{L}$ ) was purchased from Sciyu Biotech Co. Ltd. (China). Phospholipon $90 \mathrm{G}$ with purity of $97 \%$ phosphatidylcoline was kindly provided by Lipoid GmbH (Germany). Gallic Acid standard (Merck, Germany), Carbopol Ultrez 30 (Lubrizol, USA), solvents and other chemical reagents used were analytical grade.

\section{Animals}

In this study, white female rats (Sprague Dawley strain), aged 2-3 months and weight about 150-200 g were provided by Bogor Agricultural University (Indonesia).

\section{Total phenolic content in grape seed extract}

A calibration curve of a standard solution of gallic acid was made. Concentration of the sample solution was $1000 \mu \mathrm{g} / \mathrm{ml}$. Then, it was diluted to obtain six different concentrations ranged from 100 to $600 \mu \mathrm{g} / \mathrm{ml}$. The solution was taken in a test tube $(0.2 \mathrm{~mL})$ and added with $1.5 \mathrm{~mL}$ of $10 \%$ Folin-Ciocalteu reagent solution. All the experimental test tubes were kept at room temperature in a dark place for $5 \mathrm{~min}$. Then $1.5 \mathrm{~mL}$ of $6 \%$ $\mathrm{Na}_{2} \mathrm{CO}_{3}$ was added to each test tube and the mixture was kept in a dark place at room temperature for $90 \mathrm{~min}$. Following the incubation, the absorbance of each sample was analyzed using UV-visible spectrophotometer at a wavelength $720 \mathrm{~nm} .^{13}$

\section{Phytosome formulation}

The required amounts of GSE and Phospholipon $90 \mathrm{G}$ with three different mass ratios (Table 1) was dissolved in ethanol 96\%. The mixture was stirred at a temperature not exceeded than $40^{\circ} \mathrm{C}$ for $2 \mathrm{~h}$. The mixture was then evaporated and the dried residues were collected and placed into a desiccator overnight. Phytosomes were prepared by thin layer hydration method using rotary vacuum evaporator. The GSE-Phosholipon complex was dissolved in dichloromethane and then inserted into a round bottom flask. The flask was attached to a rotatory evaporator, and rotated at $180 \mathrm{rpm}$. The solvent was evaporated at $39^{\circ} \mathrm{C}$ under reduced pressure to obtain film inside of the wall of flask. Nitrogen gas was flown into the thin layer, and it was stored in the refrigerator up to $24 \mathrm{~h}$. The casted film was dispersed into phosphate buffer solution ( $\mathrm{pH}$ 5.5). After the phytosome suspension was formed, ultra-sonication was conducted for $10 \mathrm{~min}$

\section{Phytosome characterization Morphology}

Vesicles morphology of phytosome was visually observed using a FEI Tecnai G2 20 S-Twin (USA) Transmission Electron Microscope (TEM). Samples were shed on a carbon-coated copper grid, then the droplet was dried at room temperature and colored using phosphotungstic acid

Table 1: The phytosome formulation.

\begin{tabular}{cccc} 
& \multicolumn{3}{c}{ Concentration } \\
\cline { 2 - 4 } Materials & F1 & F2 & F3 \\
& $(1: 0,5)$ & $(1: 1)$ & $(1: 2)$ \\
\hline $\begin{array}{c}\text { Grape seed extract (GSE) } \\
\text { (gram) }\end{array}$ & 1 & 1 & 1 \\
$\quad \begin{array}{c}\text { Phospholipon 90 G } \\
\text { (gram) }\end{array}$ & 0.5 & 1 & 2 \\
$\begin{array}{c}\text { Phosphate buffer saline pH } \\
\text { 5.5 (ml) }\end{array}$ & ad 25 & ad 25 & ad 25 \\
\hline
\end{tabular}

solution. The grid was left for $30 \mathrm{~min}$ and the films were viewed using a transmission electron microscope and the results were documented.

\section{Particle size distribution and zeta potential}

The vesicle size and potential zeta were analyzed by dynamic light scattering system spectroscopy using a Malvern Zetasizer Nano Z (UK) computerized system.

\section{Fourier transformation infrared spectroscopy (FTIR)}

FTIR spectra were obtained using an FTIR spectrometer (Shimadzu FTIR-8400). Samples were mixed with dry crystalline $\mathrm{KBr}$ in a ratio of 1:100 and pellets were prepared. The mixture was triturated into fine powder using an agate mortar before compressing into $\mathrm{KBr}$ disc. Each $\mathrm{KBr}$ disc was scanned for each sample within the wave number region $4000-400 \mathrm{~cm}^{-1}$. The IR spectra of Phospholipon $90 \mathrm{G}$, pure GSE, physical mixture of Phospholiphon $90 \mathrm{G}$ and GSE and GSE phytosome were analyzed as comparisons.

\section{The Entrapment Efficiency}

The phytosome suspension was centrifuged at $4500 \mathrm{rpm}$ for $60 \mathrm{~min}$. The supernatant was discarded, and the precipitate was collected and dissolved in methanol. The solution was then analyzed by UV-Vis spectrophotometer to determine its total phenolic content as the marker of GSE. Entrapment efficiency was calculated by the formula as follows:

$$
\mathrm{EE}(\%)=\frac{\text { GSE concentration measured }}{\text { GSE concentration in theoretical formula }} \times 100 \%
$$

\section{Serum Preparation}

Carbopol Ultrez 30 was dispersed in demineralized water, and then homogenized. Triethanolamine (TEA) was added into the dispersion and homogenized to obtain a gel base. Propylene glycol which was used to dissolve methyl and propyl paraben, was added to the gel base and then homogenized. Sodium metabisulfite was dissolved in demineralized water and added to the gel base. Once the gel was formed, concentrated phytosome GSE was added into the basis, and GSE was dispersed for the control. Both gel serums were homogenized for $15 \mathrm{~min}$. The serum formulation was presented in Table 2.

\section{Physicochemical Evaluation of Serum Dosage Forms}

Physicochemical evaluations of gel based serum including organoleptic test (color, odor, syneresis), homogeneity, pH, viscosity and rheology properties was conducted.

\section{In vitro Penetration Test}

The abdomen skin of female Sprague Dawley rats aged 2-3 months was used as a membrane in the test. All of the methods for sacrificing the animals have been approved by ethics Committee from Cipto Mangunkusumo Hospital, Faculty of Medicine, Universitas Indonesia number 199/UN2.F1/ETIK/2017. The test was performed using Franz diffusion cells with a diffusion area of $1.43 \mathrm{~cm}^{2}$ and $17 \mathrm{ml}$ compartment volume. The receptor compartment was filled with phosphate buffer solution ( $\mathrm{pH}$ 5.5) and stirred with a magnetic stirrer at speed of $300 \mathrm{rpm}$. The skin was placed in the donor compartment receptor with position of the stratum corneum facing upwards. A sample of $1.0 \mathrm{~g}$ was applied to the skin surface. Then, at several time intervals $(15,30,45,60$, and 90 min then $2,3,4,6,8,10,12,14,16$, and $18 \mathrm{~h})$ samples $(1.0 \mathrm{~mL})$ was taken from the receptor compartment and was refilled with the same amount of phosphate buffer solution ( $\mathrm{pH}$ 5.5). The samples were inserted into vials and its total phenolic content was determined by Folin Ciocalteu method. 
Table 2: The serum formulation of the GSE phytosome.

\begin{tabular}{ccc}
\hline \multirow{2}{*}{ Materials } & \multicolumn{2}{c}{ Concentration (\%) } \\
\cline { 2 - 3 } & Phytosomal Serum & $\begin{array}{c}\text { Non Phytosomal } \\
\text { Serum }\end{array}$ \\
\hline GSE Phytosome & 10 & - \\
GSE & - & 4.63 \\
Carbopol Ultrez 30 & 0.5 & 0.5 \\
Triethanolamine (TEA) & 0.4 & 0.4 \\
Propilene glycol & 10 & 10 \\
Methylparabene & 0.18 & 0.18 \\
Propylparabene & 0.02 & 0.02 \\
Sodium metabisulfite & 0.075 & 0.075 \\
Deminerilized water & ad 100 & ad 100 \\
\hline
\end{tabular}

Table 3: The characteristics of the GSE phytosomes.

\begin{tabular}{ccccc}
\hline $\begin{array}{c}\text { Phytosome } \\
\text { Formula }\end{array}$ & Morphology & $\begin{array}{c}\mathrm{D}_{\text {mean }} \\
\text { volume } \\
(\mathbf{n m})\end{array}$ & $\begin{array}{c}\text { Zeta Potential } \\
(\mathbf{m V})\end{array}$ & $\begin{array}{c}\text { Entrapment } \\
\text { Eficiency } \\
(\%)\end{array}$ \\
\hline F1 & Spherical & 123.08 & -32.1 & $32.06 \pm 0.27$ \\
F2 & Spherical & 398.23 & -25.2 & $75.01 \pm 0.25$ \\
F3 & Spherical & 476.78 & -10.9 & $85.67 \pm 0.56$ \\
\hline
\end{tabular}

\section{RESULTS}

\section{Total Phenolic Content in Grape Seed Extract}

Based on the analysis, the absorbance obtained was then calculated from the calibration curve, the calculated average total phenolic content in the GSE was $568.89 \pm 15.38 \mathrm{mg}$ GAE/gram extract (GAE $=$ Gallic Acid Equivalent).

\section{Morphology of Phytosome}

TEM analysis as presented in Figure 1 confirmed the spherical shape of the vesicle. The aggregation between vesicles was observed in single particle shape, forming irregular large size particles.

\section{Particle Size Distribution and Zeta Potential}

The results for particle size distribution and zeta potential demonstrated in Table 3. F1 had an average diameter volume $123.08 \mathrm{~nm}, \mathrm{~F} 2$ at $398.23 \mathrm{~nm}$ and $\mathrm{F} 3$ was $476.78 \mathrm{~nm}$. The results also showed that $\mathrm{F} 1$ has a zeta potential value of $-32.1 \mathrm{mV}$ and $\mathrm{F} 2$ was $-25.2 \mathrm{mV}$.

\section{Fourier transformation infrared spectroscopy (FTIR)}

FTIR spectra showed some peaks that confirmed the presence of chemical interaction between GSE and phospholipids demonstrated in Figure 3.

\section{The Entrapment Efficiency}

The entrapment efficiency obtained from F1, F2, and F3 were $32.06 \pm$ $0.27 \%, 75.01 \pm 0.25 \%$, and $85.67 \pm 0.56 \%$, respectively.

\section{Formulation of Selected Phytosome}

The formula that has a spherical morphology, a high percentage of entrapped drug, small particle size, polydispersity index $<0.5$ and the zeta potential that was more negative than -30 or more positive than $+30 \mathrm{mV}$, was chosen to be incorporated into a gel-based serum dosage form. Based on the characterization, F2 was selected because of its spherical

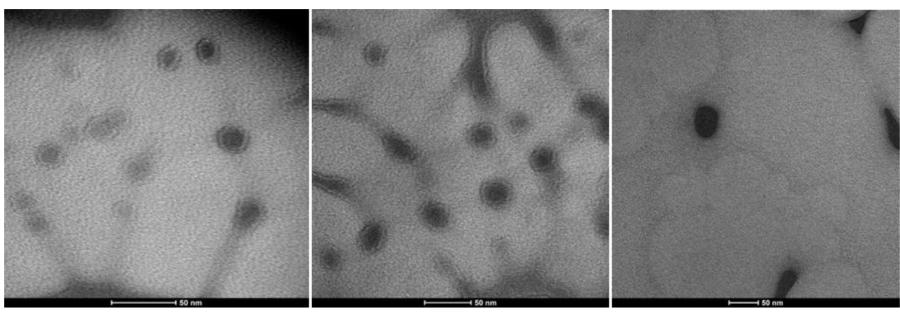

Figure 1:Transmission electron micrographs of phytosome F1 at 195,000x magnification (left), F2 at 145,000x magnification (middle), and F3 at 97,000x magnification (right).

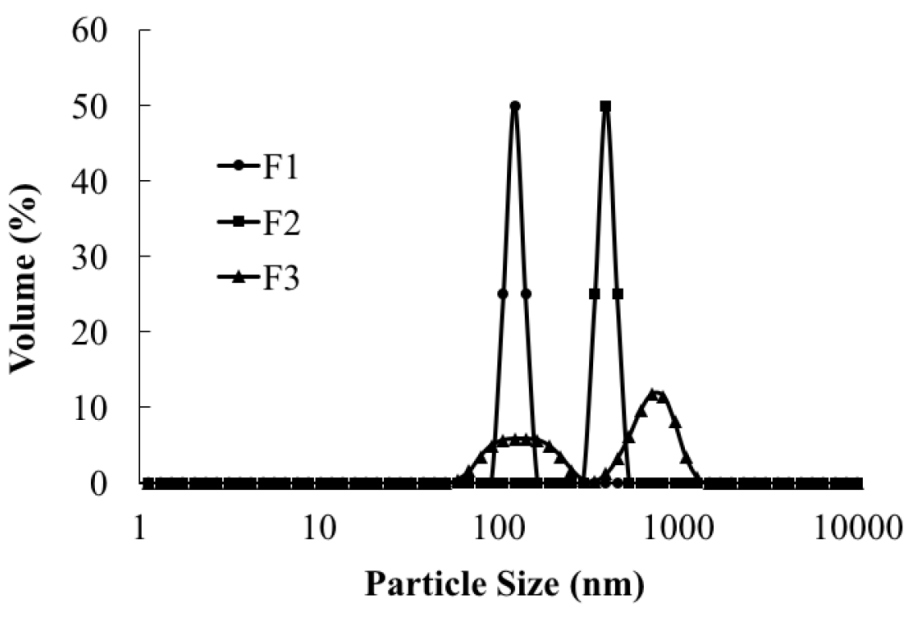

Figure 2: Particle size distribution curve of F1, F2, and F3.

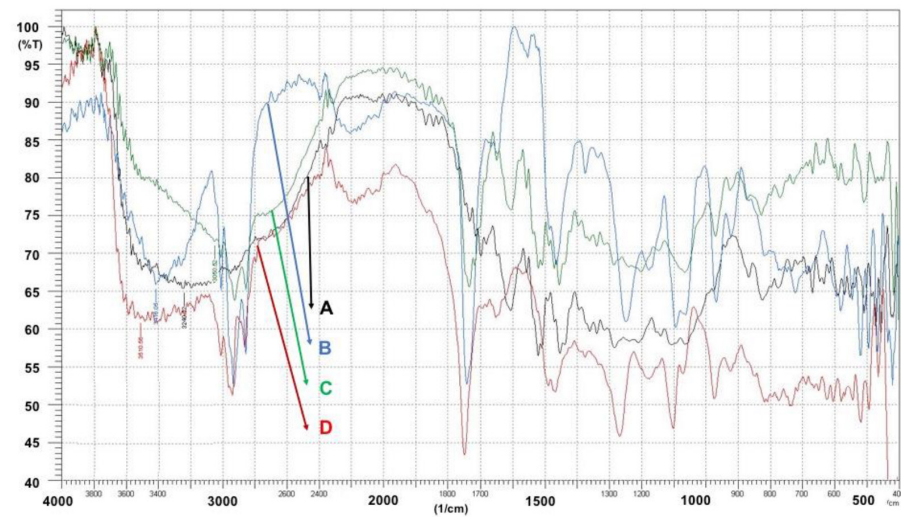

Figure 3: FTIR spectrum of GSE (A), pure phospholipon $90 \mathrm{G}(\mathrm{B})$, phytosome (C), and physical mixture (D).

shape; D mean particle size by volume value at $4147.83 \mathrm{~nm}$; polydispersity index value of 0.486; zeta potential value was $25.2 \mathrm{mV}$ and a high percentage of drug entrapped value $(75.01 \pm 0.25 \%)$. F3 has the highest percentage of drug entrapped with $85.67 \pm 0.56 \%$. However, F3 does not meet the requirements for another characteristic.

\section{Physicochemical Evaluation of Serum Dosage Forms}

Phytosome serum color was brown (Pantone $161 \mathrm{C}$ ), while the nonphytosome serum was reddish brown (Pantone $2315 \mathrm{XGC}) .{ }^{14}$ Both serums gave the typical aroma of GSE and has a homogeneous organoleptic when smeared on a glass slide. The $\mathrm{pH}$ value of phytosome serum and non-phytosome serum were 5.67 and 4.87, respectively. Viscosity 


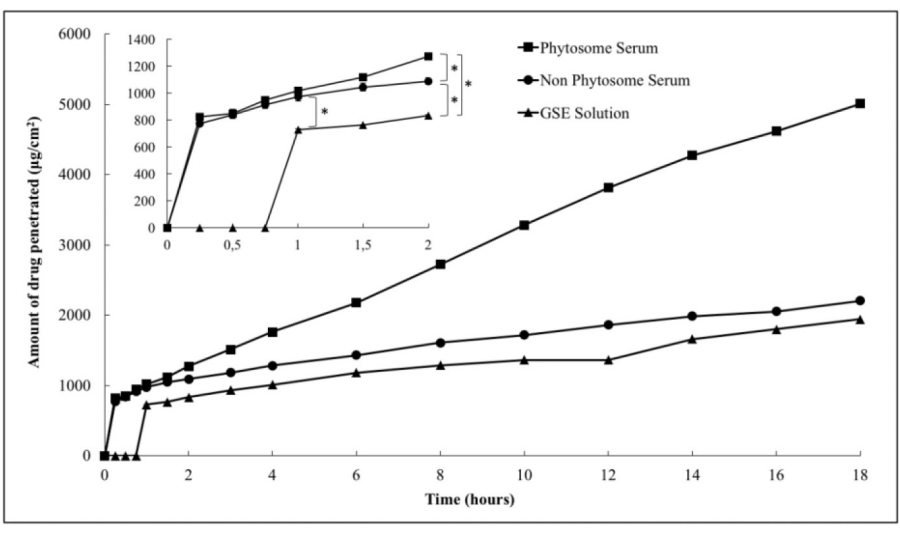

Figure 4: Cumulative of total phenolic gallic acid equivalent penetrated. All values were represented as mean $\pm S D(n=3) .\left(^{*}\right) p<0.05$.

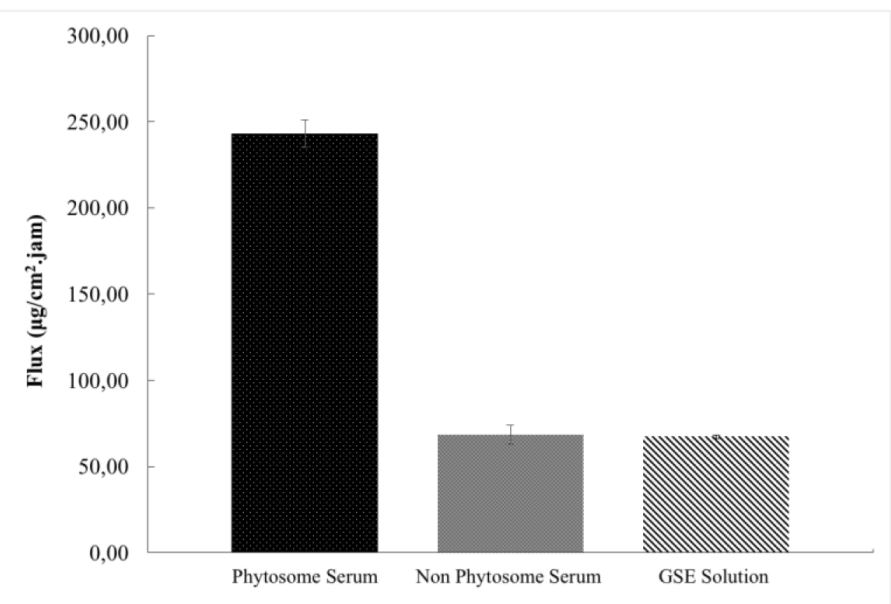

Figure 5: Average penetration flux of phytosome serum, non phytosome serum and GSE solution (average $\pm S D, n=3$ ).

measurements at a speed of $20 \mathrm{rpm}$ for phytosome serum and non phytosome serums were $2500 \mathrm{cps}$ and $465 \mathrm{cps}$, respectively.

\section{In vitro Permeation Study}

In the permeation test performed for $18 \mathrm{~h}$ (Figure 4), phytosome serum resulted a higher amount of total phenolic penetrated at $5008.81 \pm 122.33$ $\mu \mathrm{g} / \mathrm{cm}^{2}$ that was equal to gallic acid compared to non-phytosome serum with only $2206.54 \pm 90.34 \mu \mathrm{g} / \mathrm{cm}^{2}$, and GSE solution at $1940.01 \pm 75.12$ $\mu \mathrm{g} / \mathrm{cm}^{2}$. Percentage of total phenolic penetrated from phytosome serum was $27.25 \pm 0.67 \%$. This result was higher than non-phytosome serum and GSE solution which were only $11.97 \pm 0.49 \%$ and $10.63 \pm 0.41 \%$, respectively. The penetration profile in Figure 4 showed that the phytosome serum curve began to form a linear line and yields the correlation coefficient ( $r$ ) which was closest to one since the minute 15 with $r=0.99904$. However, the starting point of linear regression equation for non phytosome serum was since $2 \mathrm{~h}$ with $\mathrm{r}$ value $=0.99534$ and GSE solution since hour 1 with $r=0.98991$. The results showed that serum containing phytosome had significantly higher flux (t-test, $\mathrm{P}<0.05)$ than serum containing only extracts without phytosome modification, as well as with grape seed extract solution. The flux values of steady-state conditions on phytosome serum, non-phytosome serum, and grape seed extract solutions were $243.11 \pm 7.94 \mu \mathrm{g} / \mathrm{cm}^{2}$.hours, $68.56 \pm 5.54 \mu \mathrm{g} / \mathrm{cm}^{2}$.hours, and $67.31 \pm$ $1.00 \mu \mathrm{g} / \mathrm{cm}^{2}$.hours, respectively (Figure 5 ).

\section{DISCUSSION}

\section{Phytosome Formulation and Characterization}

Thin layer hydration method was chosen because this method is relatively easy to implement and capable to produce relatively stable vesicles during the storage. There are some variables that may influence the production of phytosome vesicles, such as evaporation time, hydration time, hydration media, and temperature. The rotational speed of the flask demonstrated the discernible influence on the thickness and uniformity of the lipid film. ${ }^{15}$ Selection of hydration solvent basically refers to the stability of active ingredients, formula application, final dosage form, and administration route. In this study, the use of phosphate buffer solution at pH 5.5 was selected because GSE is stable at low $\mathrm{pH}$, and it is suitable with skin $\mathrm{pH}$ balance.

Particle size is an important parameter in transdermal drug delivery. It can be seen in Figure 2 that F1 and F2 were distributed homogeneously, while F3 was heterogeneous with its double peaks. The high lipid composition in the formulation also increased the tendency for the formation of agglomerates, resulting in the bigger size particles. The zeta potential is a measure of the magnitude of the electrostatic potential or the repulsive force among the suspension particles. ${ }^{16}$ The value affects the uniformity of dispersion system which is not quickly settles. On the other hand, F3 with a potential zeta value only $-10.9 \mathrm{mV}$ tends to flocculate faster than F1 and F2 with more negative zeta value. The more positive or negative the zeta potential obtained, the greater the repulsive force generated between the particles. This creates particle tendency to aggregate and become smaller in size. ${ }^{17} \mathrm{~A}$ stable suspension has a zeta potential value more positive than $+30 \mathrm{mV}$ or more negative than $-30 \mathrm{mV} .{ }^{16}$ The negative charge produced from the ethanol used in phytosome preparation may prevent the aggregation of vesicles due to electrostatic repulsion and resistance force.

The spectrum of GSE showed bands at $3240,52 \mathrm{~cm}^{-1}(-\mathrm{OH})$ which intensity was decreased in phytosome form. The spectrum also changed from broad spectrum in GSE into sharp spectrum in phytosome form. Entire peaks of both GSE and Phospholipon $90 \mathrm{G}$ were shown at their physical mixture spectrum indicating no chemical interaction occurred in physical mixture.

The difference in the ratio of phospholipid and GSE greatly affects the amount of incorporated GSE in phytosome. The higher ratio of phospholipids in a vesicular system will enhance the ability to entrap drugs. ${ }^{18}$

\section{Physicochemical Evaluation of Serum Dosage Forms}

The $\mathrm{pH}$ was acidic due to the mostly acidic content presented in compound from GSE such as gallic acid and proanthocyanidins. In phytosomes, the active ingredient was not entrapped in the vesicle but bound to the polar surface of the phosphatidylcholine, so that the properties of the acid possessed would remain in effect during the formulation of the serum dosage form.

Phytosome serum had a higher viscosity due to the presence of phospholipid in formulations. Both gels were thixotropic with a plastic flow property. Plastic flow curve does not pass through the point $(0.0)$ and has a yield value. Yield value is a linear line extrapolated from the linear to the axis of the shearing stress. Preparations with this rheology property will not flow when the shear stress does not pass the yield value. Thixotropic indicate that the decline curve on the left ascending curve which means that when a shear stress, the structure takes the time to get back to the original condition. ${ }^{19}$

\section{In vitro Permeation Study}

At the first hour, the cumulative amount of GSE solution was not very high and significantly different (t-test, $\mathrm{P}<0.05$ ) when compared to both 
phytosome and non-phytosome serums. However, a significant difference $(\mathrm{P}<0.05)$ cumulative amount between phytosome and non phytosome serums began to be observed since the second hour. The phytosome complex with a strong and stable hydrogen bond formed between the polar phospholipid group and the hydrophilic active substance. This formed complex may increase drug bioavailability and skin absorption. ${ }^{20}$ The flux was determined in steady state and obtained from the linear curve slope. Flux is obtained from the comparison between the cumulative numbers of penetration to time. ${ }^{17}$ The flux value between control serum and grape seed extract solution that tends to be similar is estimated due to the content contained in both samples is also the same, i.e. grape seed extract without phytosome modification. In addition, the $\mathrm{pH}$ of the two samples are not much different that it does not significantly affect the penetration. Another thing that might affect penetration is the viscosity of the sample. A solution with a lower viscosity should penetrate better than a thicker control serum. However, the GSE which not dispersed evenly in the solution makes the viscosity effect invisible.

\section{CONCLUSION}

This research concluded that phytosome could increase the penetration of total phenolic compound in the grape seed extract in serum dosage form.

\section{ACKNOWLEDGEMENT}

The authors gratefully acknowledge to Directorate of Research and Community Engagements of Universitas Indonesia for fnancial support.

\section{CONFLICT OF INTEREST}

The authors have no conflict of interest

\section{ABBREVIATIONS}

EE: Entrapment efficiency; FTIR: Fourier Transform Infrared; GAE: Gallic Acid Equivalent; GSE: Grape Seed extract; TEA: Triethanolamine TEM: Transmission Electron Microscopy; UV-Vis: Ultraviolet-Visible.

\section{SUMMARY}

In this study, the phytosome of grape seed extract was prepared by thin layer hydration method, then applied in production of a gel-based serum. The phytosome serum containing grape seed extract could increase the penetration of total phenolic compound through the rat skin.

\section{REFERENCES}

1. Jara-Palacios M, Gordillo B, González-Miret M, Hernanz D, Escudero-Gilete M, Heredia F. Comparative Study of the Enological Potential of Different Winemaking Byproducts: Implications in the Antioxidant Activity and Color Expression of Red Wine Anthocyanins in a Model Solution. J Agric Food Chem. 2014;62(29):6975-83.
2. Teixeira A, Baenas N, Dominguez-Perles R, Barros A, Rosa E, Moreno D, et al. Natural Bioactive Compounds from Winery By-Products as Health Promoters: A Review. Int J Mol Sci. 2014;15(9):15638-78.

3. Dang $Y$, Zhang H, Xiu Z. Microwave-assisted aqueous two-phase extraction of phenolics from grape (Vitis vinifera) seed. J Chem Technol Biotechnol. 2013;89(10):1576-81

4. Yamakoshi J, Otsuka F, Sano A, Tokutake S, Saito M, Kikuchi M, et al. Lightening Effect on Ultraviolet-Induced Pigmentation of Guinea Pig Skin by Oral Administration of a Proanthocyanidin-Rich Extract from Grape Seeds. Pigment Cell Res. 2003;16(6):629-38.

5. Herrling T, Jung K, Fuchs J. Measurements of UV-generated free radicals/reactive oxygen species (ROS) in skin. Spectrochim Acta A Mol Biomol Spectrosc. 2006;63(4):840-5.

6. Chang T. An Updated Review of Tyrosinase Inhibitors Int J Mol Sci. 2009;10(6):2440-75

7. Chen M, Yu S. Lipophilized Grape Seed Proanthocyanidin Derivatives as Novel Antioxidants. J Agric Food Chem. 2017;65(8):1598-605.

8. Venkateswarlu I, Reddy J, Ramesh V. Reddy, Pravallika san Suneetha. A Review on Liposome. Res J Pharmaceut. Bio Chem Sci. 2011;2:739-51.

9. Varde N, Mehta N, Thakor N, Shah V, Upadhyay. Phytosomes: A potential phospholipid nanoparticulate carrier for the bioavailability enhancement of herbal extracts. Pharmacie Globale. 2012;3(10):1-7.

10. Lachman L, Liebermann $H$. The Theory and practice of industrial pharmacy. New Delhi: CBS Publishers and Distributors Pvt. Ltd. 2013.

11. Baki G, Alexander K. Introduction to cosmetic formulation and technology. Hoboken, New Jersey: John Wiley and Sons, Inc. 2015.

12. Shaji J, Lal M. Preparation, Optimization and Evaluation of Transfersomal Formulation for Enhanced Transdermal Delivery of a Cox-2 Inhibitor. Int J Pharm Pharm Sci. 2014;6(1):467-77.

13. Al-Saeedi A, Hossain M. Total phenols, total flavonoids contents and free radical scavenging activity of seeds crude extracts of pigeon pea traditionally used in Oman for the treatment of several chronic diseases. Asian Pac J Trop Dis. 2015;5(4):316-F21.

14. Pantone I. Simulations of Pantone Matching System Colors. New Jersey. 2004

15. Venema F, Weringa W. The interactions of phospholipid vesicles with some anti-inflammatory agents. J Colloid Interface Sci. 1988;125(2):484-92.

16. Malvern Instruments. Dynamic Light Scattering Common Terms De ned 2011;1-6.

17. Sinko $P$, Singh $Y$, Martin A. Martin's physical pharmacy and pharmaceutical sciences. Philadelphia Pa. Wolter Kluwer/Lippincott Williams and Wilkins. 2011.

18. Chaudhary H, Kohli K, Kumar V. Nano-transfersomes as a novel carrier for transdermal delivery. Int J Pharm. 2013;454(1):367-80.

19. Ramadon D, Wirarti GA, Anwar E. Novel Transdermal Ethosomal Gel Containing Green Tea (Camellia sinensis L. Kuntze) Leaves Extract: Formulation and in-vitro Penetration Study. J Young Pharm. 2017;9(3):336-40.

20. Prasad SB, Bhatia S, Singh S. Phytosome: Phytoconstituent Based Lipid Derived Drug Delivery System. J Chem Pharm Res. 2016;8(5):664-7. 